\title{
Long-term simulation of growth stage-based irrigation scheduling in maize under various water constraints in Colorado, USA
}

\author{
Quanxiao FANG (凶) ${ }^{1,2}$, Liwang MA ${ }^{3}$, Lajpat Rai AHUJA ${ }^{3}$, Thomas James TROUT ${ }^{4}$, Robert Wayne MALONE ${ }^{5}$, \\ Huihui ZHANG ${ }^{4}$, Dongwei GUI ${ }^{6}$, Qiang YU $^{2}$ \\ 1 Agronomy College, Qingdao Agricultural University, Qingdao 266109, China \\ 2 State Key Laboratory of Soil Erosion and Dryland Farming on the Loess Plateau, Northwest A\&F University, Yangling 712100, China \\ 3 USDA-ARS, Rangeland Resources and Systems Research Unit, Fort Collins, CO 80526, USA \\ 4 USDA-ARS, Agricultural Water Management and Systems Research Unit, Fort Collins, CO 80526, USA \\ 5 USDA-ARS, National Laboratory for Agriculture and the Environment, Ames, IA 50011, USA \\ 6 State Key Laboratory of Desert and Oasis Ecology, Xinjiang Institute of Ecology and Geography, Chinese Academy of Sciences, \\ Urumqi 830011, China
}

\begin{abstract}
Due to varying crop responses to water stress at different growth stages, scheduling irrigation is a challenge for farmers, especially when water availability varies on a monthly, seasonal and yearly basis. The objective of this study was to optimize irrigation between the vegetative $(\mathrm{V})$ and reproductive $(\mathrm{R})$ phases of maize under different available water levels in Colorado. Longterm (1992-2013) scenarios simulated with the calibrated Root Zone Water Quality Model were designed to meet $40 \%-100 \%$ of crop evapotranspiration (ET) requirements at $\mathrm{V}$ and $\mathrm{R}$ phases, subject to seasonal water availabilities $(300,400,500 \mathrm{~mm}$, and no water limit), with and without monthly limits (total of 112 scenarios). The most suitable irrigation between $\mathrm{V}$ and $\mathrm{R}$ phases of maize was identified as 60/100, 80/100, and 100/100 of crop ET requirement for the $300,400,500 \mathrm{~mm}$ water available, respectively, based on the simulations from 1992 to 2013. When a monthly water limit was imposed, the corresponding suitable irrigation targets between V and R stages were 60/100, $100 / 100$, and $100 / 100$ of crop ET requirement for the above three seasonal water availabilities, respectively. Irrigation targets for producing higher crop yield with reduced risk of poor yield were discussed for projected five-year water availabilities.
\end{abstract}

Keywords RZWQM, ET-based irrigation schedule, maize, water constrains

Received September 1, 2016; accepted December 8, 2016

Correspondence: fangqx@igsnrr.ac.cn

\section{Introduction}

Water is the greatest limiting factor for crop yield in arid and semiarid areas. Increasing crop yield and water use efficiency (WUE) with limited water is the key to mitigating water shortages in these regions ${ }^{[1,2]}$. One challenge is how to apply the limited available irrigation water at the right time and in the right amount to maximize grain yield and WUE under various water availabilities and climate conditions.

Several studies have investigated the effect of water stress at different growth stages on crop yield and WUE, and the relationships between grain yield, WUE and evapotranspiration (ET) in many regions, e.g., Austra$\operatorname{lia}^{[3,4]}$, China ${ }^{[5,6]}$ and USA ${ }^{[7,8]}$, have been reviewed by Du et al. ${ }^{[9]}$, Geerts and Raes ${ }^{[2]}$ and Roth et al. ${ }^{[10]}$. The main findings were that (1) crop response to water stress varied at different growth stages and the stages most sensitive to water stress were identified; (2) crop yield generally increased with the increase of evapotranspiration (ET), but decreased when ET exceeded certain levels, and WUE generally decreased before achieving maximum grain yield as ET increased; and (3) supplementary irrigation after moderate water stress induced quicker crop growth, while excessive water stress could lead a substantial reduction of grain yield.

These results provide useful information on scheduling limited irrigation water within the crop season for high WUE and grain yield. The complex response of a crop to water stress at the different stages ${ }^{[5,6,11]}$ and the varied relationships between crop yield, WUE and ET among 
seasons or areas ${ }^{[6,12,13]}$, however, constrained the application of these results from short-term experiments with limited treatments to a wide range of climate and soil conditions ${ }^{[1,14]}$. In addition, most of the experimental studies used fixed irrigation treatments and did not consider the uneven distribution of available irrigation water within growing seasons. Thus, there is a need to identify the most beneficial irrigation levels at different growth stages based on crop water requirement and soil water dynamics across a wide range of seasonal variation.

Agricultural system models, such as the DSSAT-CERES mode $^{[15]}$, AquaCrop model ${ }^{[16]}$, APSIM $^{[17]}$, CropSyst $^{[18]}$, SWAT model ${ }^{[19]}$ and RZWQM2 $2^{[20]}$, have been used to quantify the relationships between crop yield and water use for optimizing irrigation management across various seasonal conditions in arid and semiarid areas over long periods $^{[21,22]}$. Long-term simulation studies, in combination with field experimental results, can refine and extend these experimental irrigation management strategies to better cope with seasonal variation ${ }^{[1,20,23]}$. In Bolivia, Geerts et al. ${ }^{[24]}$ used the AquaCrop model to determine irrigation strategies for high WUE of quinoa which were adopted by the local farmers. On the North China Plain, Chen et al. ${ }^{[23]}$ used APSIM and long-term weather data to determine irrigation strategies (irrigation amount and times) that gave high WUE and could reduce decline of the groundwater table in the region. In the same area, Fang et al. ${ }^{[1]}$ studied the allocation of fixed amounts of irrigation water between wheat and maize seasons based on longterm simulations with RZWQM, and found that $80 \%$ of the water allocated to the critical wheat growth stages and $20 \%$ of water applied at maize planting achieved the highest WUE for both crops. Saseendran et al. ${ }^{[25]}$ used the CERES-Maize model in combination with the long-term weather data from 1912 to 2005 at Akron, CO, USA to investigate the best water allocation ratio between vegetative $(\mathrm{V})$ and reproductive $(\mathrm{R})$ phases of maize under different available seasonal irrigation levels, and developed limited irrigation management strategies for the local farmers.

Fixed irrigation scheduling throughout the growing season was used in the above simulation studies, which did not reflect crop water requirement at the most sensitive crop water stress stages. Such a fixed irrigation scheduling may not provide optimal water use ${ }^{[26,27]}$. One disadvantage of this type of scheduling is that irrigation amounts and timing do not match the crop water requirement at different growth stages, as irrigation water availability varies monthly and in different years. Recently, Fang et al. ${ }^{[20]}$ used RZWQM2 to explore the effect of various water stress levels based on crop ET demand on crop yield and WUE in eastern Colorado. The most suitable target ET levels between $\mathrm{V}$ and $\mathrm{R}$ phases were identified based on simulated crop yield and WUE under the different seasonal water availabilities in the areas, e.g., 300,400 and $500 \mathrm{~mm}$ available seasonal irrigation water levels, but the irrigation schedule optimization did not consider restrictions in the monthly water limit or projected multiple-year water allowance, which are often faced by the local farmers.

The main objective of this study was to identify the most suitable irrigation schedules for a given seasonal irrigation amount available to farmers across/within maize seasons as restricted by local water resources and management policy, such as monthly, seasonal and projected multiple-year water availability limits in a region, using long-term simulations with RZWQM2. Specifically, the grain yield and WUE in response to different targeted crop ET levels between $\mathrm{V}$ and $\mathrm{R}$ phases were quantified to derive the most efficient irrigation schedule (as percentage crop ET demand) and amounts between $\mathrm{V}$ and $\mathrm{R}$ stages of maize for different monthly and yearly water availabilities.

\section{Materials and methods}

\subsection{Field experiment and model evaluations}

The field experimental data used for model evaluations were obtained from a study conducted from 2008 to 2011 near Greeley, Colorado, USA $\left(40.45^{\circ} \mathrm{N}, 104.64^{\circ} \mathrm{W}\right)$. The soil is a sandy loam and is fairly uniform throughout the $200 \mathrm{~cm}$ soil profile. Six irrigation treatments (microirrigation with surface drip tubing adjacent to each row) with four replicates were designed to meet a specified percentage of potential crop ET requirements ${ }^{[28,29]}$ during the growing seasons: $100 \%$ (T1), 85\% (T2), 75\% (T3, received 5\% more water than $\mathrm{T} 4$ ), $70 \%$ (T4), 55\% (T5) and $40 \%$ (T6) of potential crop ET. The amount of irrigation water drip-irrigated for each treatment was estimated on a weekly basis based on reference ET demand, crop coefficient, rainfall, and soil water deficit. The T1 treatment was irrigated such that water availability (irrigation plus precipitation plus stored soil water) was adequate to meet crop water requirements, as predicted by the reference evapotranspiration and crop coefficients (FAO-56 methodology ${ }^{[29]}$ ). Adequacy was monitored by ensuring the soil water content remained in the plant readily-available range. The remaining treatments were irrigated to achieve total water applications (irrigation plus precipitation) that approximated the target treatment amounts. Maize cv. Dekalb 52-59 was planted at an average rate of 81000 seeds per hectare with $0.76 \mathrm{~m}$ row spacing in early May from 2008 to 2011. A detailed description of the experiment is provided by Ma et al. ${ }^{[30]}$ and Fang et al. ${ }^{[20]}$, and the experimental data set and detailed methodology can also be found at the US Department of Agriculture National Agricultural Library Ag Data Commons (https://data.nal.usda.gov/dataset/ usda-ars-colorado-maize-water-productivity-dataset-20082011).

The Root Zone Water Quality Model (RZWQM2, version 2.0$)^{[31]}$ with the DSSAT 4.0 crop modules was 
used in this study ${ }^{[32]}$. RZWQM2 uses the Green-Ampt equation to estimate infiltration and the Richards equation to estimate soil water redistribution. The modified BrooksCorey equations are used to describe the soil water retention curve and the saturated hydraulic conductivity is estimated using an empirical relationship with effective porosity ${ }^{[31]}$. The model provides options to calculate hourly and daily potential ET (PET) based on the Shuttleworth-Wallace method ${ }^{[33]}$. The irrigation amount was determined to meet a certain percentage of the RZWQM2 simulated PET with Shuttleworth-Wallace equation minus the rainfall during the irrigation interval. The irrigation interval and seasonal amount limit can be set as inputs for the ET-based irrigation management option in the model. This irrigation method based on ShuttleworthWallace estimated potential ET was tested with field data and showed agreement with measured irrigation amounts and crop yield within acceptable standard deviation of the data $^{[30]}$.

Model calibration was evaluated with all the measured data from all six treatments for all four years. An automatic optimization and parameter estimation software (PEST) ${ }^{[34]}$ was incorporated in RZWQM, and provided the option to calibrate the model automatically. The overall four years (2008-2011) of simulations of ET, grain yield, and biomass showed a similar trend with the measured data across the six irrigation treatments, with $r^{2}$ values of 0.81 , 0.98 and 0.90 , respectively. The corresponding relative root mean square error $(\mathrm{RRMSE}=\mathrm{RMSE} /$ mean measured data, where RMSE is root mean standard error calculated based on measured and simulated data) values were $9.7 \%$, $4.2 \%$ and $7.0 \%$, respectively (Tables $1-4$ in Fang et al. ${ }^{[20]}$. Detailed information on the model evaluation has been provided by Fang et al. ${ }^{[20]}$.

2.2 Long-term simulations (1992-2013) scenarios and data analysis

After calibration by Fang et al. ${ }^{[20]}$, the model was applied to long-term simulations (1992-2013) of corn ET and yield for various irrigation management scenarios. In these longterm simulations, $\mathrm{N}$ was applied at $150 \mathrm{~kg} \cdot \mathrm{hm}^{-2}$ as ureaammonium-nitrate at planting. Corn was planted on 12 May and harvested at physiological maturity as determined by the model, which was between late September and early October. Drip irrigation was applied every 3 days after planting (the irrigation rate is treated as a low intensity rain storm with intensity less than the saturated hydraulic conductivity and no runoff occurring in the field) and ended on or before 16 September each year. Other management, such as planting density, row space, fertilizer application and tillage, was according to the described experimental procedure. Based on the experimental data (83-90 days after planting for R1 stage of maize) and the long-term simulations (71-89 days after planting for $75 \%$ silking, averaged 80 days after planting), it was assumed that the reproductive stage started 77 days after planting (start of R1 stage for maize). This fixed division between $\mathrm{V}$ and $\mathrm{R}$ phases for maize did not account for the variations in $\mathrm{V}$ and $\mathrm{R}$ phases associated with weather variations (irrigation management effect on maize growth stage was small in the model). The fixed division between $\mathrm{V}$ and $\mathrm{R}$ phases was a simple and acceptable way for average longterm simulation results across many years. Irrigation was scheduled to meet a certain percentage of crop ET demand (40\%, 60\%, 80\% and $100 \%$ ET during past 3 days) at both V (before R1 stage) and R stages (after R1 stage: R1-R6, including maturation stage), which resulted in 16 irrigation scenarios (e.g., 40\%-40\%, 40/40ET; 40\%-60\%, 40/60ET; $40 \%-80 \%, 40 / 80 \mathrm{ET}$ between the $\mathrm{V}$ and $\mathrm{R}$ stages). These 16 scenarios were simulated with 300,400 and $500 \mathrm{~mm}$ or no seasonal water limits, for a total of $16 \times 4=64$ scenarios. For the 48 scenarios with seasonal irrigation water limits, the amount of available water was applied without constraints until all the available water was exhausted or alternatively was allocated monthly so that irrigation was further limited by monthly maximum available water. For the Greeley, Colorado experimental site, the percentage of water available for each month (e.g., monthly maximum available water amount) during the corn season was $1.7 \%$, $17.4 \%, 24.0 \%, 27.6 \%, 21.8 \%$ and $6.2 \%$, respectively, of the total available water resource from April to September, based on Colorado Division of Water Resources diversion records from 2002 to 2009 (http://water.state.co.us/DivisionsOffices/Div1SPlatteRiverBasin/Pages/Div1SPlatteRB.aspx). Thus, for each of the seasonal water limited scenarios $(300,400$ and $500 \mathrm{~mm})$, it was simulated with or without monthly limits on water supply. As a result, there are $64+48=112$ irrigation scenarios in this long-term study, and the model was run continuously from 1 January 1992 to 17 December 2013. Other management practices apart for irrigations were the same as the experimental management practices from 2008 to 2011 .

Based on the long-term simulations under no water limit conditions, the summation of irrigation requirement, average crop yield and WUE were calculated for a moving 5-year period from 1992 to 2013 at the targeted ET levels, and used for analysis of irrigation management for a fiveyear projected water availability in the region.

\section{Results}

\subsection{Irrigation scheduling without water limit}

Under the no seasonal water limit condition, the simulated results for the 16 targeted ET levels (percentage of crop ET) represented the maximum irrigation amount and yield limited by these treatments for the local conditions (Fig. 1). Any reduction in simulated irrigation amount and grain yield with the seasonal water limitation (e.g., 300, 400 and $500 \mathrm{~mm}$ ), in comparison with the no water limit condition, 


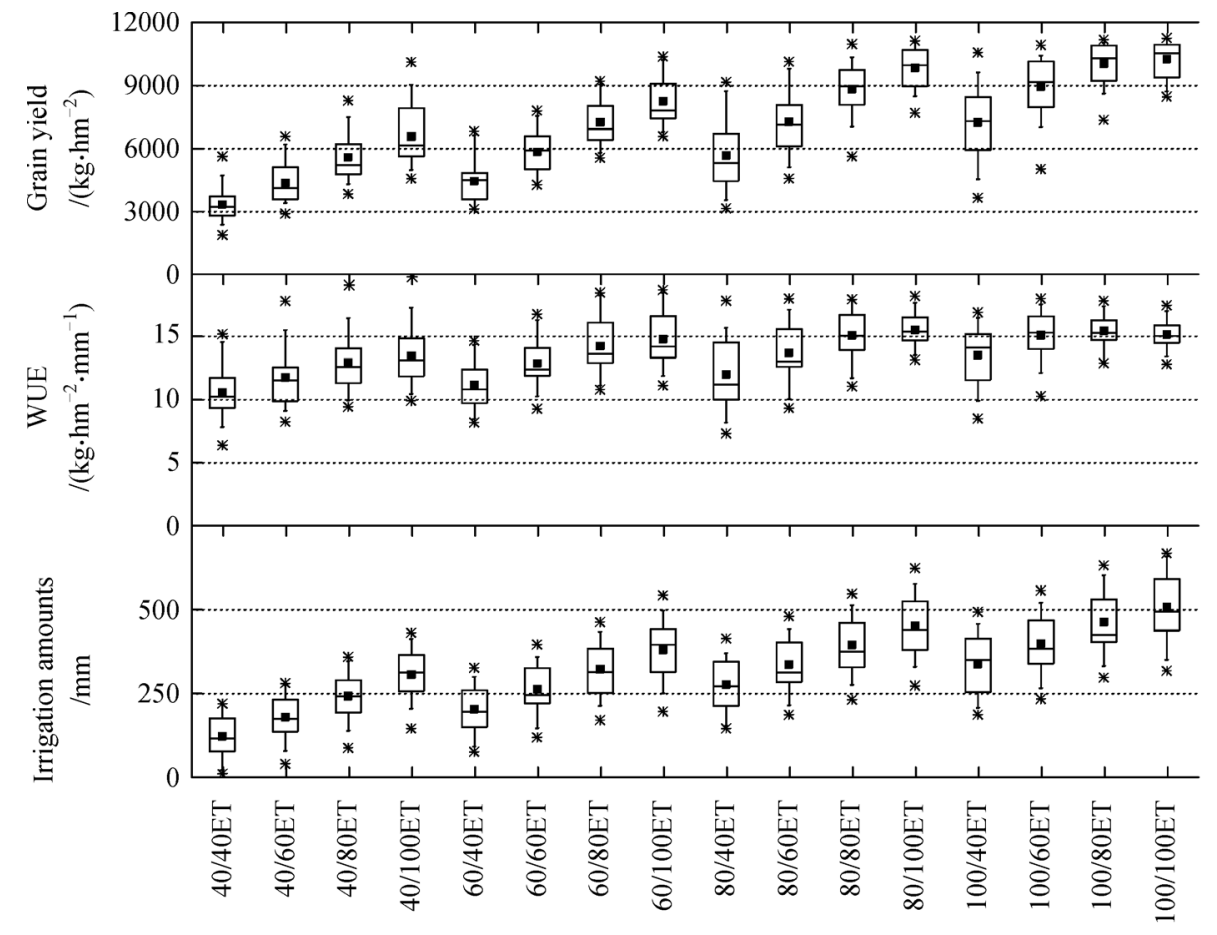

Fig. 1 Simulated grain yield $\left(\mathrm{kg} \cdot \mathrm{hm}^{-2}\right.$ ), water use efficiency (WUE, $\mathrm{kg} \cdot \mathrm{hm}{ }^{-2} \cdot \mathrm{mm}^{-1}$ ) and irrigation amounts (mm) in response to these targeted irrigation levels (40\%-100\% of crop ET requirement) under the no water limit condition from 1992 to 2013 at Greeley CO. The box plots show $5,25,50,75,95$ percentiles. The dots and lines in the box plots indicate the mean and medium values across these years, respectively. The crosses indicate the minimum and maximum values across these years.

indicated late season irrigation deficits exceeding those created by these irrigation levels. The simulated long-term average grain yield ranged from $3340 \mathrm{~kg} \cdot \mathrm{hm}^{-2}$ for $40 /$ 40ET to $10256 \mathrm{~kg} \cdot \mathrm{hm}^{-2}$ for $100 / 100$ ET from 1992 to 2013 (dry grain yield basis without moisture), and the corresponding average irrigation requirements were simulated from $123 \mathrm{~mm}$ for 40/40ET to $509 \mathrm{~mm}$ for 100/100ET across these years. The simulated average WUE values ranged from $10.6 \mathrm{~kg} \cdot \mathrm{hm}^{-2} \cdot \mathrm{mm}^{-1}$ for $40 / 40 \mathrm{ET}$ to $15.5 \mathrm{~kg} \cdot \mathrm{hm}^{-2} \cdot \mathrm{mm}^{-1}$ for $80 / 100 \mathrm{ET}$ (Fig. 1). Detailed analysis of the no water limit condition is reported by Fang et al. ${ }^{[20]}$.

\subsection{Irrigation scheduling with $500 \mathrm{~mm}$ seasonal water} supply

The simulated crop yield, WUE and irrigation amounts across seasons increased with increase in targeted ET levels (percentage crop ET) under the $500 \mathrm{~mm}$ water available conditions without (Fig. 2a) or with (Fig. 2b) monthly water limit. The 100/100ET irrigation level produced the highest grain yield with and without monthly water limit, similar to the no water limit condition (Table 1; Fig. 1; Fang et al. ${ }^{[20]}$ ).

Although the 100/100 ET irrigation level had the highest simulated average crop yield, the irrigation level of 80 / 100ET produced the highest average WUE for the $500 \mathrm{~mm}$ seasonal water available without and with a monthly water limit (Fig. 2). However, there was little difference (1.3\%$3.4 \%$ ) in simulated WUE across seasons among the irrigation levels of 80/100ET, 100/80ET and 100/100ET. A similar result was also obtained for the no water limit condition (Fig. 1; Fang et al. ${ }^{[20]}$ ). Considering both simulated grain yield and WUE for these irrigation levels (Fig. 2), the most suitable targeted ET level was 100/ 100ET for unlimited and $500 \mathrm{~mm}$ seasonal water available with or without monthly water limit.

The average simulated irrigation amounts from 1992 to 2013 generally increased with the increase in irrigation levels from $40 \%$ ET to $100 \%$ ET under $500 \mathrm{~mm}$ irrigation water available. According to the simulated irrigation water requirement without water limit (Fig. 1), the $500 \mathrm{~mm}$ seasonal available water could meet the targeted ET levels of $80 / 100 \mathrm{ET}$ and $100 / 80 \mathrm{ET}$ in about $75 \%$ of the crop seasons from 1992 to 2013 (Fig. 2a). When the monthly water limit was imposed, however, the $500 \mathrm{~mm}$ available water could meet the targeted irrigation level of 60/40ET only in about $50 \%$ of the crop seasons from 1992 to 2013 (Fig. 2b)

Due to the discrepancy between crop irrigation requirement and irrigation available constrained by the monthly water limit, $500 \mathrm{~mm}$ seasonal water only fully met the 40 / 40ET and 60/40ET irrigation levels (Fig. 2b), and was unable to meet the requirement for other higher targeted ET levels, compared with no monthly water limit conditions (Fig. 2a vs. Fig. 2b). Thus, it is difficult to 
Table 1 Long-term (1992-2013) simulated average corn yield (GY, $\left.\mathrm{kg} \cdot \mathrm{hm}^{-2}\right)$ and water use efficiency $\left(\mathrm{WUE}, \mathrm{kg} \cdot \mathrm{hm}^{-2} \cdot \mathrm{mm}^{-1}\right)$ across seasons for different irrigation targets (40\%-100\% of crop ET) between vegetative and reproductive stages under various water availability without or with monthly water limit (Numbers in bold are the most reasonable irrigation targets with the highest grain yield and WUE for each water limit conditions)

\begin{tabular}{|c|c|c|c|c|c|c|c|c|c|}
\hline \multirow{3}{*}{ Water limit } & \multirow{3}{*}{$\begin{array}{l}\text { Targets for } \\
\text { reproductive } \\
\text { stage }\end{array}$} & \multicolumn{8}{|c|}{ Targets for vegetative stage } \\
\hline & & \multicolumn{2}{|c|}{$40 \% \mathrm{ET}$} & \multicolumn{2}{|c|}{$60 \% \mathrm{ET}$} & \multicolumn{2}{|c|}{$80 \%$ ET } & \multicolumn{2}{|c|}{$100 \% \mathrm{ET}$} \\
\hline & & GY & WUE & GY & WUE & GY & WUE & GY & WUE \\
\hline & & \multicolumn{8}{|c|}{ No monthly water limit } \\
\hline & $40 \% \mathrm{ET}$ & 3340 & 10.6 & 4447 & 11.2 & 5674 & 12.0 & 7245 & 13.5 \\
\hline Unlimited & $60 \% \mathrm{ET}$ & 4363 & 11.8 & 5854 & 12.9 & 7261 & 13.7 & 8941 & 15.1 \\
\hline \multirow[t]{2}{*}{ water } & $80 \%$ ET & 5582 & 12.9 & 7249 & 14.2 & 8834 & 15.1 & 10051 & 15.4 \\
\hline & $100 \% \mathrm{ET}$ & 6584 & 13.5 & 8260 & 14.8 & 9846 & 15.5 & 10256 & 15.1 \\
\hline $300 \mathrm{~mm}$ & $40 \% \mathrm{ET}$ & 3340 & 10.6 & 4427 & 11.1 & 5292 & 11.6 & 5088 & 10.6 \\
\hline seasonal & $60 \% \mathrm{ET}$ & 4363 & 11.8 & 5654 & 12.8 & 5963 & 12.3 & 5730 & 11.3 \\
\hline \multirow[t]{2}{*}{ water limit } & $80 \%$ ET & 5519 & 13.0 & 6707 & 14.2 & 6456 & 12.9 & 5930 & 11.5 \\
\hline & $100 \% \mathrm{ET}$ & 6298 & 13.6 & 7113 & 14.6 & 6620 & 13.0 & 5940 & 11.6 \\
\hline $400 \mathrm{~mm}$ & $40 \% \mathrm{ET}$ & 3340 & 10.6 & 4447 & 11.2 & 5666 & 12.0 & 6903 & 13.2 \\
\hline seasonal & $60 \% \mathrm{ET}$ & 4363 & 11.8 & 5854 & 12.9 & 7124 & 13.6 & 7962 & 14.4 \\
\hline \multirow[t]{2}{*}{ water limit } & $80 \%$ ET & 5582 & 12.9 & 7211 & 14.2 & 8241 & 14.9 & 8665 & 14.8 \\
\hline & $100 \%$ ET & 6554 & 13.5 & 8048 & 14.9 & 8834 & 15.3 & 8800 & 14.9 \\
\hline $500 \mathrm{~mm}$ & $40 \%$ ET & 3340 & 10.6 & 4447 & 11.2 & 5674 & 12.0 & 7245 & 13.5 \\
\hline seasonal & $60 \% \mathrm{ET}$ & 4363 & 11.8 & 5854 & 12.9 & 7261 & 13.7 & 8854 & 15.1 \\
\hline \multirow[t]{3}{*}{ water limit } & $80 \%$ ET & 5582 & 12.9 & 7249 & 14.2 & 8782 & 15.1 & 9791 & 15.5 \\
\hline & $100 \% \mathrm{ET}$ & 6584 & 13.5 & 8251 & 14.8 & 9749 & 15.6 & 10016 & 15.4 \\
\hline & & \multicolumn{8}{|c|}{ Monthly water limit } \\
\hline $300 \mathrm{~mm}$ & $40 \% \mathrm{ET}$ & 3266 & 10.5 & 4180 & 10.9 & 4593 & 10.8 & 5048 & 11.3 \\
\hline seasonal & $60 \%$ ET & 3975 & 11.6 & 4720 & 11.7 & 5076 & 11.4 & 5459 & 11.7 \\
\hline \multirow[t]{2}{*}{ water limit } & $80 \%$ ET & 4455 & 12.5 & 5045 & 12.2 & 5221 & 11.6 & 5516 & 11.8 \\
\hline & $100 \%$ ET & 4659 & 12.8 & 5182 & 12.4 & 5222 & 11.6 & 5513 & 11.8 \\
\hline $400 \mathrm{~mm}$ & $40 \% \mathrm{ET}$ & 3319 & 10.6 & 4333 & 11.0 & 5253 & 11.5 & 5649 & 11.6 \\
\hline seasonal & $60 \% \mathrm{ET}$ & 4166 & 11.8 & 5383 & 12.5 & 5960 & 12.2 & 6451 & 12.5 \\
\hline \multirow[t]{2}{*}{ water limit } & $80 \%$ ET & 4866 & 12.8 & 6081 & 13.6 & 6381 & 12.7 & 6761 & 12.7 \\
\hline & $100 \% \mathrm{ET}$ & 5270 & 13.4 & 6366 & 13.9 & 6477 & 12.8 & 6901 & 12.9 \\
\hline $500 \mathrm{~mm}$ & $40 \% \mathrm{ET}$ & 3340 & 10.6 & 4431 & 11.2 & 5563 & 11.9 & 6339 & 12.4 \\
\hline seasonal & $60 \% \mathrm{ET}$ & 4243 & 11.8 & 5666 & 12.8 & 6795 & 13.2 & 7662 & 13.8 \\
\hline \multirow[t]{2}{*}{ water limit } & $80 \%$ ET & 5088 & 12.8 & 6675 & 14.2 & 7743 & 14.4 & 8166 & 14.2 \\
\hline & $100 \% \mathrm{ET}$ & 5656 & 13.6 & 7179 & 14.8 & 8048 & 14.7 & 8401 & 14.3 \\
\hline
\end{tabular}

meet the targeted ET levels, especially during the R phases, when these monthly water limits are imposed, suggesting other methods, such as different cropping systems or planting dates or water conservation methods are needed to cope with the monthly water limit condition.

3.3 Irrigation scheduling with $400 \mathrm{~mm}$ seasonal water supply

Under the $400 \mathrm{~mm}$ available seasonal water condition, the simulated highest average grain yields was obtained for the
80/100ET irrigation level without monthly water limit (Table 1; Fig. 3a), and for the 100/100ET irrigation level with monthly water limit (Fig. 3b). No significant difference (below 3.4\%) in simulated grain yield across seasons was found among the irrigation levels of 80/ $100 \mathrm{ET}, 100 / 80 \mathrm{ET}$ and $100 / 100 \mathrm{ET}$ under no monthly water limit. When the monthly water limit was imposed, however, higher grain yield across seasons was simulated for the 100/100ET than for the 80/100ET irrigation level (6.5\%, Table 1).

For the $400 \mathrm{~mm}$ available water without monthly water 


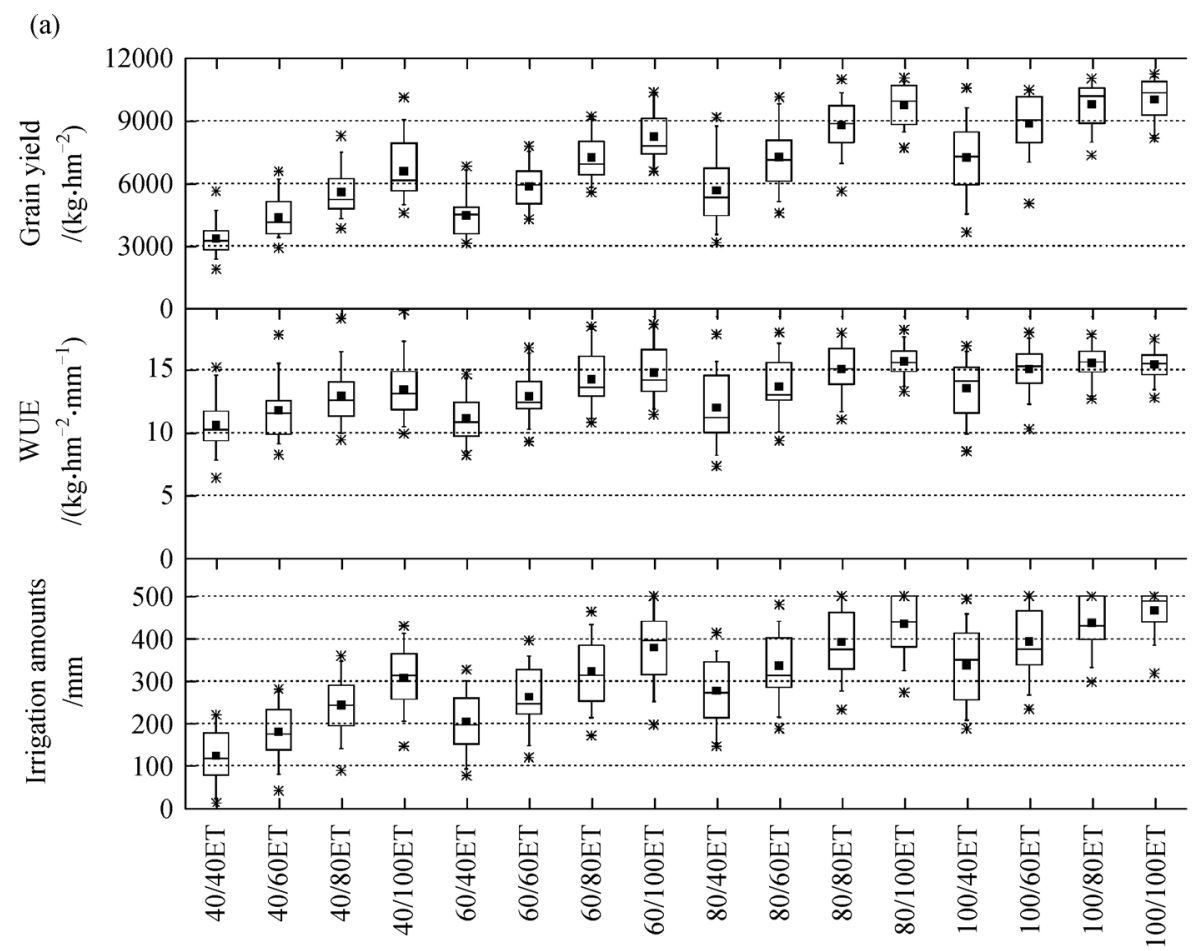

(b)

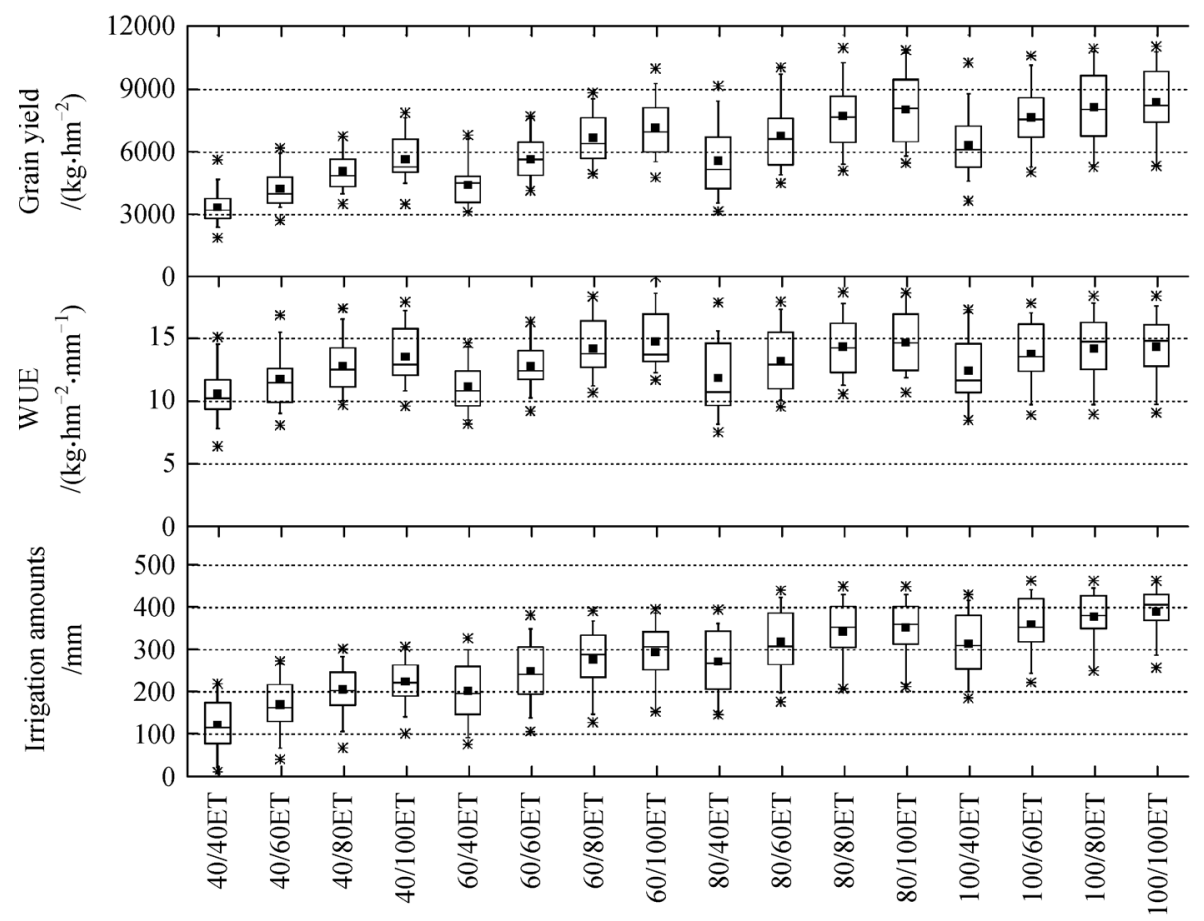

Fig. 2 Simulated grain yield $\left(\mathrm{kg} \cdot \mathrm{hm}^{-2}\right)$, water use efficiency (WUE, $\mathrm{kg} \cdot \mathrm{hm}{ }^{-2} \cdot \mathrm{mm}^{-1}$ ) and irrigation amounts (mm) in response to these targeted irrigation levels (40\%-100\% of crop ET requirement) under the $500 \mathrm{~mm}$ seasonal water availability without monthly water limitation (a) and with monthly water limitation (b) from 1992 to 2013 at Greeley CO. The box plots show 5, 25, 50, 75, 95 percentiles. The dots and lines in the box plots indicate the mean and medium values across these years, respectively. The crosses indicate the minimum and maximum values across these years. 


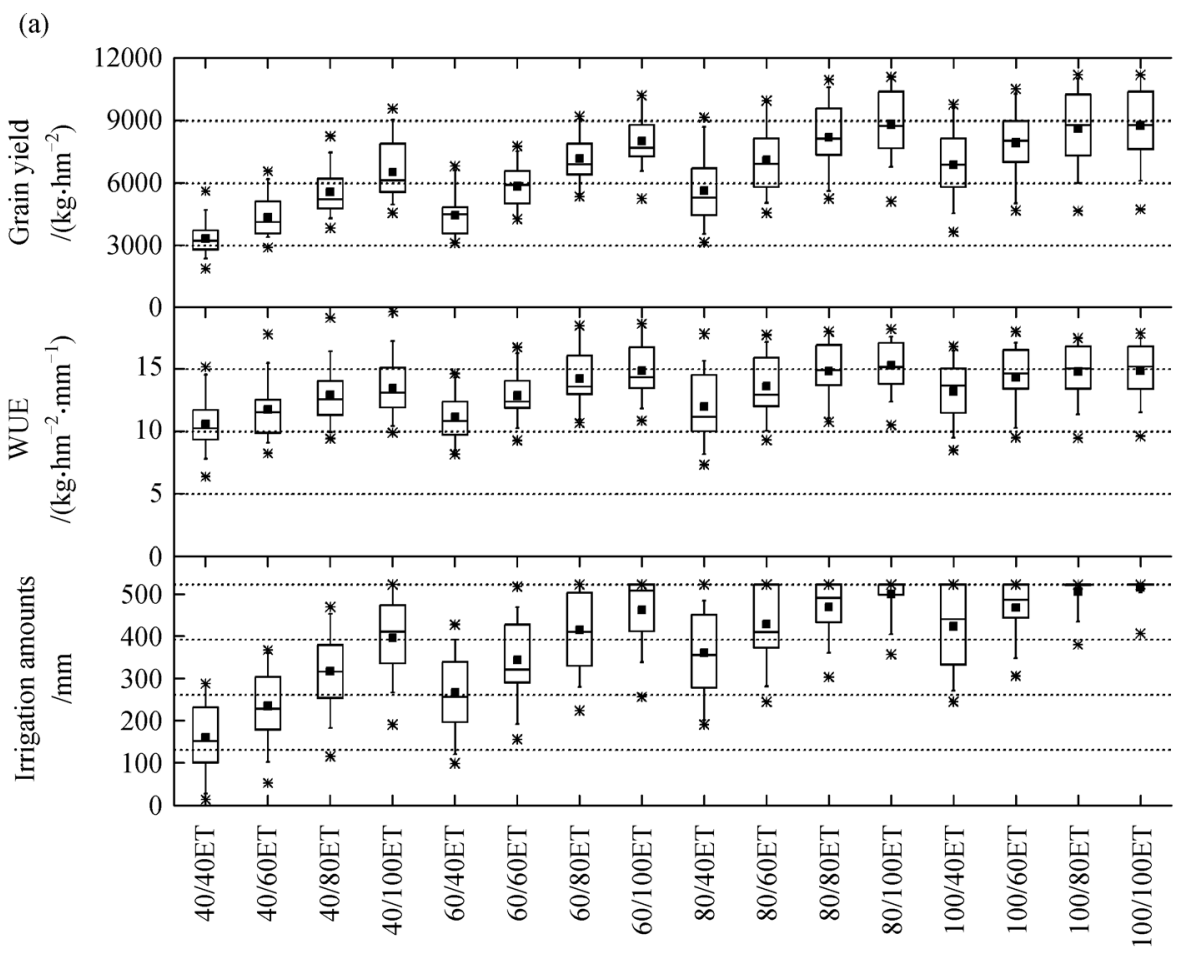

(b)

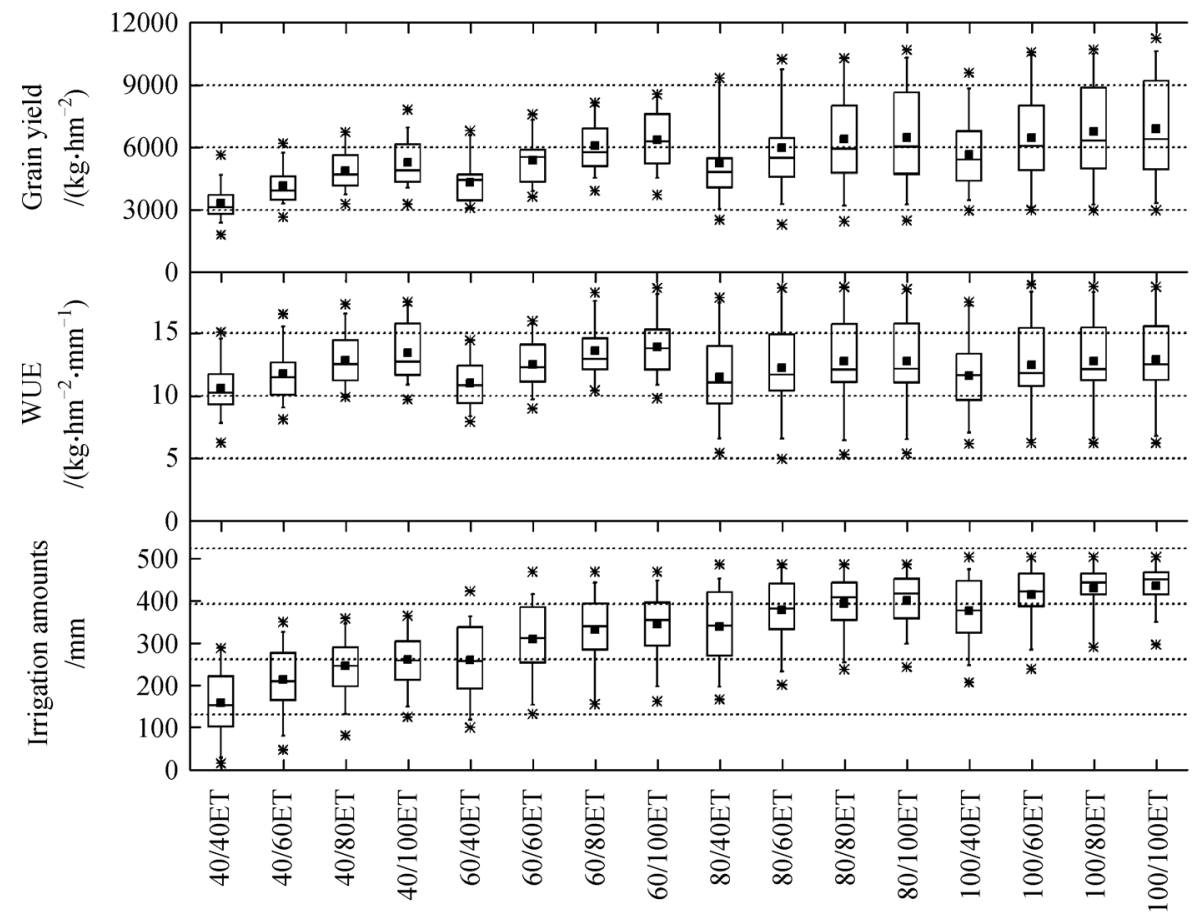

Fig. 3 Simulated grain yield $\left(\mathrm{kg} \cdot \mathrm{hm}^{-2}\right)$, water use efficiency (WUE, $\mathrm{kg} \cdot \mathrm{hm} \mathrm{m}^{-2} \cdot \mathrm{mm}^{-1}$ ) and irrigation amounts (mm) in response to these targeted irrigation levels (40\%-100\% of crop ET requirement) under the $400 \mathrm{~mm}$ seasonal water availability without monthly water limitation (a) and with monthly water limitation (b) from 1992 to 2013 at Greeley CO. The box plots show 5, 25, 50, 75, 95 percentiles. The dots and lines in the box plots indicate the mean and medium values across these years, respectively. The crosses indicate the minimum and maximum values across these years. 
limit, the irrigation level with the highest average crop yield (80/100ET) also produced highest WUE across seasons (Table 1; Fig. 3a), compared with other irrigation treatments of 100/80ET and 100/100ET. When a monthly water limit was imposed, the highest average WUE was simulated at 60/100ET irrigation level, but showed less difference from the irrigation level of 100/100ET (7.7\% vs. 8.4\%; Table 1; Fig. 3b). Considering both simulated grain yield and WUE (Fig. 3), the most suitable targeted ET levels under the $400 \mathrm{~mm}$ water available condition were recommended as 80/100 ET without monthly water limit, and 100/100ET with monthly water limit.

The average simulated irrigation amounts from 1992 to 2013 with no monthly water limit generally increased with the increase in targeted ET levels, and reached $400 \mathrm{~mm}$ at 80/100ET irrigation level (Fig. 3a). According to the simulated irrigation water requirement with no water limit (Fig. 1), the $400 \mathrm{~mm}$ seasonal available water could meet the targeted ET levels of 60/80ET, 80/60ET and 100/40ET in about $75 \%$ of the crop seasons from 1992 to 2013 (Fig. 3a). When the monthly water limit was imposed, the $400 \mathrm{~mm}$ seasonal available water could only meet the targeted ET level of 60/40ET in about 50\% of the crop seasons from 1992 to 2013. When the targeted ET levels were above $60 \%$ ET (e.g., $80 \%$ or $100 \%$ ET) during the V phases, serious water deficit occurred during the $\mathrm{R}$ phases and resulted in high seasonal variations in grain yield (standard deviations were more than $2000 \mathrm{~kg} \cdot \mathrm{hm}^{-2}$ for the 80/100ET, 100/80ET and 100/100ET). On the other hand, suitable lower targeted ET levels during the V phases with high targeted ET during R phases (e.g., 60/100ET) produced relatively lower seasonal variations in simulated grain yield (Fig. 3b)

\subsection{Irrigation scheduling with $300 \mathrm{~mm}$ seasonal water supply}

Under $300 \mathrm{~mm}$ seasonal water available without monthly water limits, the highest average grain yield was simulated at the 60/100ET irrigation level (Table 1; Fig. 4a). Increasing irrigation levels for the $\mathrm{V}$ phases (e.g., $80 \%$ $100 \%$ ET) resulted in lower simulated grain yield with higher seasonal variations, mainly caused by water stress during the $\mathrm{R}$ phases after the available water supply had been used (Fig. 4a). When the monthly water limit was imposed, the simulated highest average grain yield was at 100/80ET irrigation level, but there was little difference (below 6.4\%) in simulated grain yield across seasons among the 60/100ET, 80/100ET, 100/80ET and 100/ 100ET irrigation levels (Table 1).

At $300 \mathrm{~mm}$ available water without monthly water limits, the 60/100ET irrigation level also produced the highest WUE across seasons, compared with the targeted ET levels of 80/100ET, 100/80ET and 100/100ET (Table 1; Fig. 4a). When the monthly water limit was imposed, the highest average WUE across seasons was also obtained at 60/100ET level, but showed little difference (5.1\%) from the $80 / 100$ ET, 100/80ET and 100/100ET levels (Table 1; Fig. 4b). Considering both simulated highest grain yield and WUE (Fig. 4), the most suitable irrigation level was $60 / 100 \mathrm{ET}$ for the $300 \mathrm{~mm}$ seasonal available water without or with monthly water limits.

The simulated average seasonal irrigation amounts reached $300 \mathrm{~mm}$ at 60/100ET irrigation level. Compared to the simulated full irrigation water requirement with no seasonal water limit (Fig. 1), the $300 \mathrm{~mm}$ seasonal water could meet the targeted irrigation level of 40/80ET in about 75\% of the crop seasons from 1992 to 2013 (Fig. 4a). When the monthly water limit was imposed, however, it could only meet the targeted 40/40ET irrigation level in about 50\% of the crop seasons from 1992 to 2013 (Fig. 4b).

3.5 Seasonal irrigation strategies under the different water constraints

A detailed comparison of simulated crop yield, WUE and irrigation amount from 1992 to 2013 was presented for the selected irrigation management scenarios for each water constraint condition (Fig. 5). The simulated irrigation water requirements with no seasonal water limit $(100 /$ 100ET) ranged from 320 to $670 \mathrm{~mm}$ across these seasons. The above irrigation amounts higher than $500 \mathrm{~mm}$ were simulated for half of these seasons (Fig. 5a) but with little increase in crop yield and substantially reduced WUE for these seasons (Fig. 5b, Fig. 5c), compared to the 80/100ET irrigation level with $400 \mathrm{~mm}$ seasonal water available. Among the identified best irrigation levels for each seasonal water limit, about $20 \%$ of the crop seasons can meet the targeted ET levels of 60/100ET with $300 \mathrm{~mm}$ water available, $30 \%$ of the seasons at $80 / 100 \mathrm{ET}$ with $400 \mathrm{~mm}$ water available, and $60 \%$ of the seasons at 100 / $100 \mathrm{ET}$ with $500 \mathrm{~mm}$ water available, respectively (Fig. 5a). When the monthly water limit was imposed, the 300,400 or $500 \mathrm{~mm}$ seasonal available water did not meet the targeted ET levels of 60/100ET, 100/100ET or 100/100ET across these seasons (Fig. 5a).

Both simulated irrigation amount and crop yield increased with the increase in targeted ET levels from $60 / 100$ ET to $100 / 100$ ET under the various seasonal water limits regardless of monthly water limit (Fig. 5b). Compared to the targeted ET level of 100/100ET with $500 \mathrm{~mm}$ available water with monthly water limits (Fig. 2b), the targeted ET level of 80/100ET (400 mm available water) without monthly water limit produced higher crop yield for most seasons (Fig. 3a) with very similar average irrigation amount of about $400 \mathrm{~mm}$ (Fig. 2b; Fig. 3a). This result indicated a substantial negative impact on maize yield by imposing monthly water limit in the region even with the high total seasonal water 


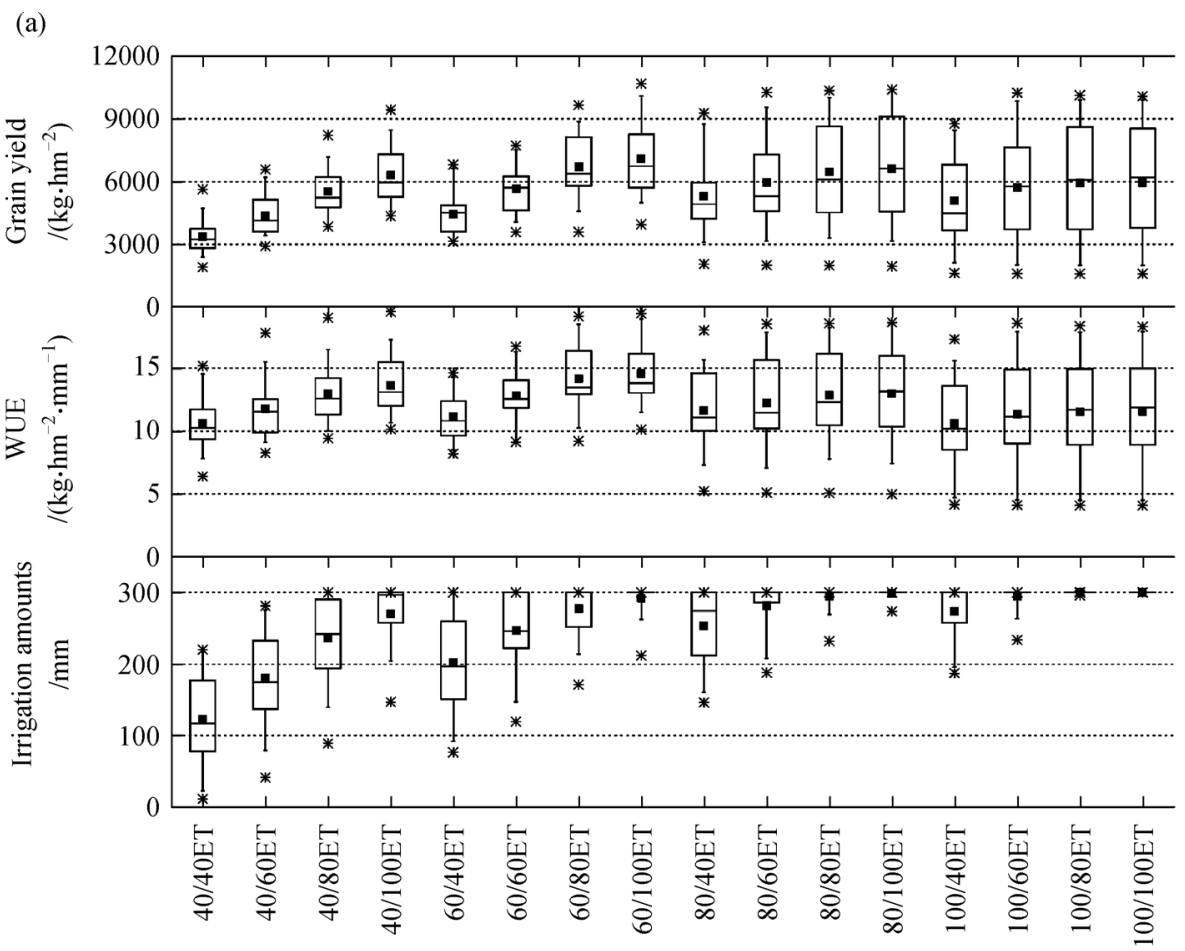

Fig. 4 Simulated grain yield $\left(\mathrm{kg} \cdot \mathrm{hm}^{-2}\right.$ ), water use efficiency (WUE, $\mathrm{kg} \cdot \mathrm{hm} \mathrm{m}^{-2} \cdot \mathrm{mm}^{-1}$ ) and irrigation amounts (mm) in response to these targeted irrigation levels (40\%-100\% of crop ET requirement) under the $300 \mathrm{~mm}$ seasonal water availability without monthly water limitation (a) and with monthly water limitation (b) from 1992 to 2013 at Greeley CO. The box plots show 5, 25, 50, 75, 95 percentiles. The dots and lines in the box plots indicate the mean and medium values across these years, respectively. The crosses indicate the minimum and maximum values across these years. 

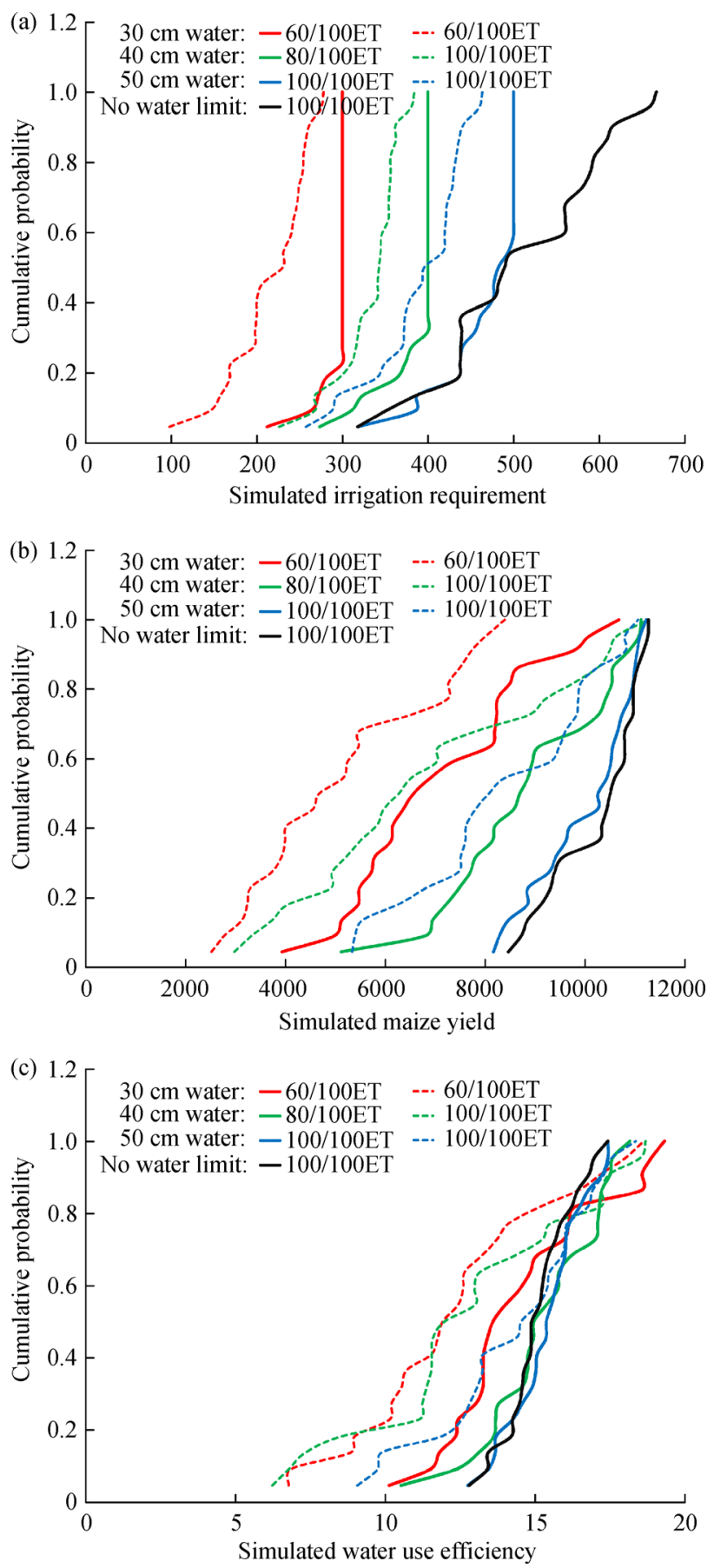

Fig. 5 Cumulative probabilities of simulated irrigation requirement $(\mathrm{mm})(\mathrm{a})$, grain yield $\left(\mathrm{kg} \cdot \mathrm{hm}^{-2}\right)(\mathrm{b})$, and water use efficiency $\left(\mathrm{kg} \cdot \mathrm{hm}^{-2} \cdot \mathrm{mm}^{-1}\right)$ (c) from 1992 to 2013 for the selected reasonable irrigation management scenarios under the different water availabilities without (solid lines) or with (dash lines) monthly water limit.

available (Fig. 2b).

Under no monthly water limit, the simulated WUE values were similar between $80 / 100 \mathrm{ET}$ with $400 \mathrm{~mm}$ seasonal water available, 100/100ET with $500 \mathrm{~mm}$ seasonal water available or no water limit condition, while 60/100 ET with $300 \mathrm{~mm}$ seasonal water available produced lower WUE in most seasons (Fig. 5c), and higher seasonal variations in WUE (Fig. 4a). When monthly water limits were imposed, the simulated WUE was generally lower compared with the simulated WUE without monthly water limit. For similar average irrigation amounts, higher WUE for the 80/100ET irrigation level under $400 \mathrm{~mm}$ water available without monthly water limit was simulated than for the 100/100ET irrigation level under $500 \mathrm{~mm}$ water available with monthly water limit (Fig. 5a, Fig. 5c).

3.6 Irrigation strategies for a five-year projected water availability

Some regions or areas impose multiple-year water limits on farmers, where the irrigation amount they can pump from groundwater is flexible across seasons as long as the total irrigation amount is less than the multiple-year water limit, such as in Kansas, USA (http://agriculture.ks.gov/ divisions-programs/dwr/water-appropriation/multi-yearflex-accounts) and Europe ${ }^{[27]}$. The total irrigation requirement, average crop yield and WUE were further analyzed for a moving 5-year period from 1992 to 2013 at the targeted ET levels under no water limit condition in the area, where all the targeted irrigation levels were fully met as indicated in Fig. 1.

The simulated crop irrigation requirement for the moving 5-year period increased from $613 \mathrm{~mm}$ for 40 / 40ET to $2532 \mathrm{~mm}$ for $100 / 100 \mathrm{ET}$, and the corresponding average grain yield and WUE for the period ranged from 3455 to $10416 \mathrm{~kg} \cdot \mathrm{hm}^{-2}$ and from 10.9 to $15.3 \mathrm{~kg} \cdot \mathrm{hm}^{-2} \cdot \mathrm{mm}^{-1}$, respectively (Table 2 ). The result was similar to the response of seasonal grain yield and WUE to targeted irrigation levels under no water limits (Fig. 1). Farmers can select the most productive irrigation levels based on the 5-year projected irrigation allowance as shown in Table 1. For example, with about $1300 \mathrm{~mm}$ irrigation amount for a 5-year period, the most productive irrigation levels were 60/60ET with higher WUE value and lower variations for grain yield and WUE, compared with the $80 / 40 \mathrm{ET}$ irrigation levels (1387 $\mathrm{mm}$ in total). With about $1600 \mathrm{~mm}$ irrigation amount for the 5-year period, the best irrigation level was $60 / 80 \mathrm{ET}$, which produced slightly lower grain yield than the alternatives but with much lower variability and higher WUE value. The above examples were based on the same targeted irrigation levels for each season during a 5-year period. However, if variable targeted irrigation levels across seasons were applied based on the rainfall amount and distribution, higher total crop yield for a 5-year period could be obtained with similar total irrigation water amounts, which requires an optimization tool to find the suitable irrigation levels for each season based on the long-term weather variations. 
Table 2 Simulated total irrigation requirement $(\mathrm{mm})$, average grain yield $\left(\mathrm{kg} \cdot \mathrm{hm}{ }^{-2}\right)$ and average water use efficiency $\left(\mathrm{WUE}, \mathrm{kg} \cdot \mathrm{hm} \mathrm{m}^{-2} \cdot \mathrm{mm}{ }^{-1}\right)$ for the five-year moving period from 1992 to 2013 as influenced by the various targeted irrigation levels (40\%-100\% of crop ET requirement) (the standard deviations were calculated from the different 5-year periods from 1992 to 2013)

\begin{tabular}{|c|c|c|c|c|c|}
\hline \multirow{2}{*}{ Items } & \multirow{2}{*}{ Targets for R stage/\% } & \multicolumn{4}{|c|}{ Targets for V Stage $/ \%$} \\
\hline & & 40 & 60 & 80 & 100 \\
\hline \multirow[t]{4}{*}{ Irrigation requirement } & 40 & $613 \pm 150$ & $1018 \pm 178$ & $1387 \pm 201$ & $1692 \pm 221$ \\
\hline & 60 & $893 \pm 153$ & $1308 \pm 184$ & $1682 \pm 211$ & $1995 \pm 229$ \\
\hline & 80 & $1201 \pm 166$ & $1604 \pm 193$ & $1972 \pm 223$ & $2311 \pm 243$ \\
\hline & 100 & $1520 \pm 171$ & $1891 \pm 217$ & $2256 \pm 226$ & $2532 \pm 237$ \\
\hline \multirow[t]{4}{*}{ Grain yield } & 40 & $3455 \pm 348$ & $4631 \pm 358$ & $6011 \pm 828$ & $7520 \pm 688$ \\
\hline & 60 & $4479 \pm 366$ & $6053 \pm 321$ & $7586 \pm 697$ & $9232 \pm 615$ \\
\hline & 80 & $5667 \pm 378$ & $7403 \pm 247$ & $9101 \pm 484$ & $10250 \pm 416$ \\
\hline & 100 & $6654 \pm 500$ & $8392 \pm 315$ & $10021 \pm 421$ & $10416 \pm 367$ \\
\hline \multirow[t]{4}{*}{ WUE } & 40 & $10.9 \pm 0.8$ & $11.5 \pm 0.6$ & $12.6 \pm 1.5$ & $14.0 \pm 1.0$ \\
\hline & 60 & $12.0 \pm 0.7$ & $13.3 \pm 0.7$ & $14.2 \pm 1.1$ & $15.5 \pm 0.8$ \\
\hline & 80 & $13.1 \pm 0.7$ & $14.5 \pm 0.8$ & $15.5 \pm 0.7$ & $15.7 \pm 0.6$ \\
\hline & 100 & $13.6 \pm 0.7$ & $15.0 \pm 0.7$ & $15.7 \pm 0.6$ & $15.3 \pm 0.6$ \\
\hline
\end{tabular}

\section{Discussion}

The simulated crop water requirement, grain yield and WUE across seasons for these various targeted ET levels can be used for managing the limited water resources in a local area ${ }^{[22]}$. For example, the targeted ET level of $60 /$ 100ET under $400 \mathrm{~mm}$ seasonal water available produced similar maize yield $\left(8047 \mathrm{~kg} \cdot \mathrm{hm}^{-2}\right)$ to the average maize yield over the same period in north-eastern $\mathrm{CO}$ (7842 $\mathrm{kg} \cdot \mathrm{hm}^{-2}$; http://quickstats.nass.usda.gov) with average seasonal irrigation amount of $350 \mathrm{~mm}$. The recommended irrigation levels between $\mathrm{V}$ and $\mathrm{R}$ phases for a certain water available level can guide local farmers to partition irrigation water between the $\mathrm{V}$ and $\mathrm{R}$ phases to achieve better grain yield and WUE. When applying these long-term simulation results, however, the farmers should be aware of the high yearly variability in grain yield and WUE associated with weather variations (Figs. 1-4).

Previous simulation studies on irrigation management with crop models focused mainly on fixed irrigation schedules and did not account for the variations in crop water requirement associated with weather conditions ${ }^{[2,15,23]}$. The refined fixed irrigation schedules from the above studies were implemented easily but with limitations for coping with seasonal weather variations

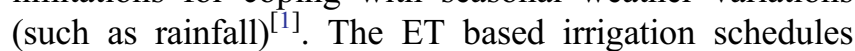
accounted for the variations in crop water requirement and can be more applicable and precise for irrigation management within season ${ }^{[20]}$.

Successfully applying long-term simulation results for farmers, however, require correctly modeling crop growth and water requirement in response to water stress levels ${ }^{[11,16,17]}$. Given that the model was calibrated with uniform stress across growth stages (e.g., 40/40ET, 60/ $60 \mathrm{ET}, 80 / 80 \mathrm{ET}$ and $100 / 100 \mathrm{ET})^{[20]}$, there is a need for the model to be further evaluated with different stress levels between the $\mathrm{V}$ and $\mathrm{R}$ phases in the future ${ }^{[30]}$. In addition, there are infinite combinations of irrigation scheduling between $\mathrm{V}$ and $\mathrm{R}$ phases for a given available irrigation water level, so only limited combinations were analyzed based on the current long-term simulation scenarios. Additional simulation scenarios with more refined irrigation levels between $\mathrm{V}$ and $\mathrm{R}$ phases should be helpful in obtaining better irrigation strategies than the current irrigation management selected from the limited cases.

\section{Conclusions}

A process-based agricultural system model and long-term weather data (1992-2013) were used to quantify irrigation requirements, maize grain yield and WUE when crop water use (ET) was restricted during V or R phases and seasonal and monthly irrigation water supply were limited. The long-term simulation results, based on the Greeley, $\mathrm{CO}$ climate, provided useful guidelines for managing limited irrigation water to maximize maize yield and WUE. Maximum predicted yields and ET allocation strategy (V and R phases) were 7113 (60/100ET), 8834 (80/100ET), $10016(100 / 100 \mathrm{ET}), 10256(100 / 100 \mathrm{ET}) \mathrm{kg} \cdot \mathrm{hm}^{-2}$ for the $300,400,500 \mathrm{~mm}$, and unlimited water supply, respectively. In all cases, for a limited seasonal water supply, irrigation should be limited during $\mathrm{V}$ stage to save water for the reproductive stage. When monthly water restrictions were applied, the simulated grain yield was reduced substantially with simulated decreased irrigation amounts, 
where the suitable targeted ET levels were 60/100ET, 100/ $100 \mathrm{ET}$ and 100/100ET for the 300, 400, $500 \mathrm{~mm}$ seasonal water availabilities. Since the ET based irrigation method accounted for the weather variation (such as evaporative demand and rainfall distribution) in the area, the suitable irrigation practices selected and the relationship between targeted ET levels and crop yield can potentially applied for different weather conditions in the area.

Acknowledgements This work was supported by the National Natural Science Foundation of China (31671627) and the 2016 Agricultural international exchange and cooperation project.

Compliance with ethics guidelines Quanxiao Fang, Liwang Ma, Lajpat Rai Ahuja, Thomas James Trout, Robert Wayne Malone, Huihui Zhang, Dongwei Gui, and Qiang Yu declare that they have no conflict of interest or financial conflicts to disclose.

This article does not contain any studies with human or animal subjects performed by any of the authors.

\section{References}

1. Fang Q X, Ma L W, Yu Q, Ahuja L R, Malone R W, Hoogenboom G. Irrigation strategies to improve the water use efficiency of wheatmaize double cropping systems in North China Plain. Agricultural Water Management, 2010, 97(8): 1165-1174

2. Geerts S, Raes D. Deficit irrigation as an on-farm strategy to maximize crop water productivity in dry areas. Agricultural Water Management, 2009, 96(9): 1275-1284

3. Bell L W, Lilley J M, Hunt J R, Kirkegaard J A. Optimizing grain yield and grazing potential of crops across Australia's high-rainfall zone: a simulation analysis. 1. Wheat. Crop \& Pasture Science, 2015, 66(4): 332-348

4. Sadras V O, Lawson C, Hooper P, McDonald G K. Contribution of summer rainfall and nitrogen to the yield and water use efficiency of wheat in Mediterranean-type environments of South Australia. European Journal of Agronomy, 2012, 36(1): 41-54

5. Zhang S, Sadras V, Chen X, Zhang F. Water use efficiency of dryland wheat in the Loess Plateau in response to soil and crop management. Field Crops Research, 2013, 151: 9-18

6. Zhang X, Wang Y, Sun H, Chen S, Shao L. Optimizing the yield of winter wheat by regulating water consumption during vegetative and reproductive stages under limited water supply. Irrigation Science, 2013, 31(5): 1103-1112

7. Lobell D B, Roberts M J, Schlenker W, Braun N, Little B B, Rejesus R M, Hammer G L. Greater sensitivity to drought accompanies maize yield increase in the U.S. Midwest. Science, 2014, 344(6183): 516-519

8. Xue Q, Rudd J C, Liu S, Jessup K E, Devkota R N, Mahano J R. Yield determination and water-use efficiency of wheat under waterlimited conditions in the US Southern High Plains. Crop Science, 2014, 54(1): 34-47

9. Du T, Kang S, Zhang J, Davies W J. Deficit irrigation and sustainable water-resource strategies in agriculture for China's food security. Journal of Experimental Botany, 2015, 66(8): 22532269
10. Roth G, Harris G, Gillies M, Montgomery J, Wigginton D. Wateruse efficiency and productivity trends in Australian irrigated cotton: a review. Crop \& Pasture Science, 2014, 64(12): 1033-1048

11. Kottmann L, Wilde P, Schittenhelm S. How do timing, duration, and intensity of drought stress affect the agronomic performance of winter rye? European Journal of Agronomy, 2016, 75: 25-32

12. Zhang S, Sadras V, Chen X, Zhang F. Water use efficiency of dryland maize in the Loess Plateau of China in response to crop management. Field Crops Research, 2014, 163: 55-63

13. Irmak S, Djaman K, Rudnick D R. Effect of full and limited irrigation amount and frequency on subsurface drip-irrigated maize evapotranspiration, yield, water use efficiency and yield response factors. Irrigation Science, 2016, 34(4): 271-286

14. Pereira L S, Paredes P, Cholpankulov E D, Inchenkova O P, Teodoro P R, Horst M G. Irrigation scheduling strategies for cotton to cope with water scarcity in the Fergana Valley, Central Asia. Agricultural Water Management, 2009, 96(5): 723-735

15. Attia A, Rajan N, Xue Q, Nair S, Ibrahim A, Hays D. Application of DSSAT-CERES-Wheat model to simulate winter wheat response to irrigation management in the Texas High Plains. Agricultural Water Management, 2016, 165: 50-60

16. Montoya F, Camargo D, Ortega J F, Córcoles J I, Domínguez A. Evaluation of Aquacrop model for a potato crop under different irrigation conditions. Agricultural Water Management, 2016, 164: 267-280

17. Amarasingha R P R K, Suriyagoda L D B, Marambe B, Gaydon D S, Galagedara L W, Punyawardena R, Howden M. Simulation of crop and water productivity for rice (Oryza sativa L.) using APSIM under diverse agro-climatic conditions and water management techniques in Sri Lanka. Agricultural Water Management, 2015, 160: $132-143$

18. Marsal J, Stöckle C O. Use of CropSyst as a decision support system for scheduling regulated deficit irrigation in a pear orchard. Irrigation Science, 2012, 30(2): 139-147

19. Sun C, Ren L. Assessing crop yield and crop water productivity and optimizing irrigation scheduling of winter wheat and summer maize in the Haihe plain using SWAT model. Hydrological Processes, 2014, 28(4): 2478-2498

20. Fang Q X, Ma L, Nielsen D C, Trout T J, Ahuja L R. Quantifying corn yield and water use efficiency under growth stage-based deficit irrigation conditions. In: Ahuja L R, Ma L, Lascano, R J, eds. Practical applications of agricultural system models to optimize the use of limited water. Adv. Agric. Systems Model. 5. ASA, SSSA, CSSA, Madison, WI. 2014, 1-24

21. Ahuja L R, Ma L, Lascano R J, Saseendran S A, Fang Q X, Nielsen D C, Colaizzi P D. Syntheses of the current model applications for managing water and needs for experimental data and model improvements to enhance these applications. Practical applications of agricultural system models to optimize the use of limited water, Adv. Agric. Systems Model. 5. ASA, SSSA, CSSA, Madison, WI. 2014, 399-438

22. Ma L, Ahuja L R, Malone R W. Systems modeling for soil and water research and management: current status and needs for the $21 \mathrm{st}$ century. Transactions of the ASABE, 2007, 50(5): 1705-1713

23. Chen C, Wang E, Yu Q. Modelling the effects of climate variability and water management on crop water productivity and water 
balance in the North China Plain. Agricultural Water Management, 2010, 97(8): 1175-1184

24. Geerts S, Raes D, Garcia M. Using AquaCrop to derive deficit irrigation schedules. Agricultural Water Management, 2010, 98(1): 213-216

25. Saseendran S A, Ahuja L R, Nielsen D C, Trout T J, Ma L. Use of crop simulation models to evaluate limited irrigation management options for corn in a semiarid environment. Water Resources Research, 2008, 44(7): 137-149

26. Linker R, Ioslovich I, Sylaios G, Plauborg F, Battilani A. Optimal model-based deficit irrigation scheduling using AquaCrop: a simulation study with cotton, potato and tomato. Agricultural Water Management, 2016, 163: 236-243

27. García-Vila M, Fereres E. Combining the simulation crop model AquaCrop with an economic model for the optimization of irrigation management at farm level. European Journal of Agronomy, 2012, 36(1): 21-31

28. Allen R G, Wright J L, Pruitt W O, Pereira L S, Jensen M E. Water requirements. In: Hoffman G J, Robert G E, Marvin E J, Derrel L M, Ronald L E. eds. Design and operation of farm irrigation systems. 2nd ed. Chap. 8. ASAE, St. Joseph, MI. 2007, 208-288
29. Allen R G, Pereira L S, Smith M, Raes D, Wright J L. FAO-56 dual crop coefficient method for estimating evaporation from soil and application extensions. Journal of Irrigation and Drainage Engineering, 2005, 131(1): 2-13

30. Ma L, Trout T J, Ahuja L R, Bausch W C, Saseendran S A, Malone R W, Nielsen D C. Calibrating RZWQM2 model for maize responses to deficit irrigation. Agricultural Water Management, 2012, 103: 140-149

31. Ahuja L R, Rojas K W, Hanson J D, Shaffer M J, Ma L. Root zone water quality model: modeling management effects on water quality and crop production. Highlands Ranch: Water Resources Publication, 2000

32. Ma L, Hoogenboom G, Ahuja L R, Ascough J C II, Saseendran S A. Evaluation of the RZWQM-CERES-Maize hybrid model for maize production. Agricultural Systems, 2006, 87(3): 274-295

33. Shuttleworth W J, Wallace J S. Evaporation from sparse crops-an energy combination theory. Quarterly Journal of the Royal Meteorological Society, 1985, 111(469): 839-855

34. Doherty J.FORTRAN 90 modules for implementation of parallelised, model-independent, model-based processing. http://www. pesthomepage.org/getfiles.php?file = modules.pdf, 2008-03-20 